Everyday reading in aphasia: Does advance picture context influence reading speed and comprehension?

Hanh Nguyen ${ }^{1} 3^{4}$, Julie Morris ${ }^{2}$, Janet Webster ${ }^{2}$, Lyndsey Nickels ${ }^{3}$

1. International Doctorate for Experimental Approaches to Language and Brain (IDEALAB), University of Potsdam, Germany, Groningen University, Netherlands, Trento University, Italy, Newcastle University, UK, and Macquarie University, Australia.

2. Speech and Language Sciences, School of Education, Communication and Language Sciences, Newcastle University, Newcastle, United Kingdom

3. Department of Cognitive Science, Macquarie University, Sydney, Australia

4. Ha Tinh University, Ha Tinh, Vietnam

Address correspondence to: Hanh Nguyen, International Doctorate for Experimental Approaches to Language and Brain (IDEALAB), University of Potsdam, Department of Linguistics, House 14, Golm, 14476 Potsdam, Germany. Email: hanhnguyen@unipotsdam.de 


\section{Everyday reading in aphasia: Does advance picture context influence reading speed and}

comprehension?

Background: Both reading speed and comprehension at the text level are often impaired in people with aphasia, potentially impacting their daily life. Provision of advance context (e.g., pictures provided to the reader prior to reading) is found to facilitate text processing and comprehension in typical readers. However, there has been no investigation of whether advance context influences reading in people with aphasia, although some studies have found no benefit on people with aphasia's comprehension accuracy from contextual supports presented simultaneously with text. It also remains unclear whether context may impact people with aphasia's understanding of any particular type of textual information (main ideas vs details, stated ideas vs implied ideas).

Aims: This study aimed to investigate the effect of advance picture context on reading speed, overall comprehension accuracy and comprehension of different types of ideas for naturalistic everyday texts in people with aphasia.

Methods \& Procedures: Twenty-nine adult typical readers and 10 people with aphasia with varying reading ability took part in the study. Participants read three matched sets of short news articles which were either preceded by a related picture, no picture, or (as fillers) an unrelated picture and were followed by multiple-choice comprehension questions. For each text, the questions assessed the understanding of a stated main idea, an implied main idea, a stated detail, and an implied detail. Mixed-effects regression analyses were performed to examine the effect of advance (related) picture context on participants' reading time and comprehension accuracy.

Outcomes \& Results: The results showed a significant effect of advance picture context on reading speed, with both typical readers and readers with aphasia showing significantly 
shorter reading times when a picture was available. Advance context did not affect overall comprehension accuracy or accuracy for any subtype of textual information for either group of participants.

Conclusion: Advance context facilitates text processing in people with aphasia, resulting in increased reading speed for everyday texts, although it does not influence their comprehension accuracy for these types of texts. This suggests that therapeutic approaches could develop more effective use of advance contextual organisers in order to increase people with aphasia's reading efficiency and ultimately, their confidence and pleasure in reading.

Keywords: reading in aphasia, reading comprehension, reading speed, authentic everyday texts, advance picture context 
Reading comprehension plays a vital role in many everyday activities, from understanding signs or menus to more complex written materials such as daily news articles in print or online. Reading ability is also essential for employment and life-long learning, and for many people, reading is more than just a required activity for work or study and is an entertaining, joyful hobby. The pleasure and ease of reading, however, is often disrupted for many people who acquire language disorders (i.e., aphasia) following brain damage. People with aphasia report they read less and reading becomes more effortful, less efficient and less pleasurable (Kjellén, Laakso, \& Henriksson, 2017; Knollman-Porter, Wallace, Hux, Brown, \& Long, 2015; Webster, Samouelle, \& Morris, 2018). Given the importance of reading, text level reading impairments can result in reduced participation in daily activities, potentially affecting quality of life for many individuals with aphasia (Parr, 1995; Webster, Morris, Howard, \& Garraffa, 2018). In addition, reading impairments can prevent some people with aphasia from engaging with professional and/or academic activities (Knollman-Porter et al., 2015).

Despite the potential impact of text reading difficulties, there is still little understanding of the nature of the text reading deficit seen in people with aphasia and about optimal interventions to improve their text reading ability (Webster et al., 2013; Webster, Morris, et al., 2018). As the ultimate rehabilitation goal is to help people with aphasia engage with everyday activities of their choice, improving their ability to read, even of simple everyday texts, will be crucial for many. Recent reviews (Purdy et al., 2018; Watter, Copley, \& Finch, 2016) of text-level reading comprehension treatment for people with acquired brain injuries, including aphasia, have reported a trend toward strategy-based approaches which generally result in positive outcomes. The trained strategies focus on factors known to influence text comprehension in typical readers (i.e., readers without brain damage who have a reading skill level typical for adults), including context. Context refers to what readers know prior to 
reading a text (i.e., background knowledge), extra-linguistic information (e.g., pictures), and/or information in the earlier parts of the text. It has been shown to play a key role in text comprehension in typical readers (Bransford \& Johnson, 1972; Kintsch, 1988). However, little is known about the role of context in reading comprehension at the text level in aphasia. The next sections review and discuss the previous research on the effects of context on text reading in typical readers and readers with aphasia.

\section{Text comprehension and contextual influences in typical readers}

Text comprehension is the process of constructing meaning from the written input and involves both linguistic (e.g., lexical and syntactic processing) and wider cognitive (e.g., working memory, attention) resources. According to Kintsch's construction-integration theory (1988), text comprehension involves two main levels of representation, the propositional text base and the situation model, that are the outcome of the construction and integration stages of processing, respectively. The text base is derived directly from the linguistic input and is described as an associative network of propositions (Kintsch, 1988). Propositions are defined as "ideas that can be expressed in words, not the words themselves" (McNamara, Miller, \& Bransford, 1991, p. 342), and they have "a truth value - that is, a proposition can be either true or false" (Harley, 2008, p. 379). A proposition usually consists of "a predicate and one or more arguments" (van Dijk \& Kintsch, 1983), for example, wash (predicate) clothes (argument). Propositions are organised in a hierarchical structure from the most important or salient to the least important (Kintsch, Kozminsky, Streby, McKoon, \& Keenan, 1975; McKoon, 1977). In addition, readers have to generate inferences to link propositions and to link between propositions and their prior knowledge (Kintsch \& van Dijk, 1978; Perrig \& Kintsch, 1985). In the construction stage, readers may make lower-level inferences such as pronoun identification (e.g., associating the pronoun "she" with a previously mentioned waitress in "The waitress didn't see us. She was serving another 
table"), simple bridging assumptions (e.g., realising that the door is the car door in "Tom parked the car. He locked the door"), or simple bridging inferences using real-world knowledge (e.g., inferring that it must have snowed during the night in "She got up in the morning and saw the backyard covered in snow").

The propositional text base is then integrated with relevant aspects of the readers' previously acquired knowledge to construct a situation model (Kintsch, 1988). At this stage, readers have to resolve any incorrect inferences they have made during the construction phase and make higher-level inferences to ensure the global coherence of the text. That is, they have to go back and link later parts of the text to earlier parts and link what is in the text with their prior knowledge. The situation model therefore represents both the literal and inferential meaning of the text that is systematically incorporated in the readers' existing knowledge (Kintsch \& Rawson, 2005; Thorndyke, 1968).

As discussed above, propositions are a key concept in text comprehension and can be distinguished by their salience (i.e., how important or salient they are in the content structure; whether they are main ideas or details). Typical readers are found to show better comprehension and recall of main ideas than details (e.g., Bransford \& Franks, 1971; Franks \& Bransford, 1972; Kintsch et al., 1975; McKoon, 1977; Walker \& Meyer, 1980). In addition, information can be explicitly stated in a text or has to be inferred by the reader (i.e., differs in its explicitness). Typical readers are found to have better performance for stated than inferred information (e.g., Graesser et al., 1994; McKoon \& Keenan, 1981; Walker \& Meyer, 1980). Previous research also found that a high level of prior background knowledge related to the text content resulted in higher accuracy for peripheral ideas in the text (e.g., Johnston, 1984; Pearson, Hansen, \& Gordon, 1979). Likewise, there was a greater facilitation from prior knowledge for implied than for stated ideas (e.g., Johnston, 1984; Pearson et al., 1979). In Kintsch's construction-integration theory, the process of text comprehension is 
completed within a context provided by the readers' prior knowledge, the information in the text itself, and/or extra-linguistic information (e.g., pictures, drawings) preceding or accompanying texts. The propositions that are included in the situational representation are the ones that are most relevant to this context.

The present study focused on the influence of pictorial context on reading comprehension accuracy and speed. Bransford and Johnson (1972) found that, when a picture or a title was provided prior to reading, participants significantly improved their self-rated comprehension and recall of textual information for an ambiguous passage (i.e., a passage about washing clothes, grammatically written but difficult to understand without a preceding context), as compared to when a picture or a title was not provided or provided after reading. The results were replicated in studies using learning materials and carried out with either developing readers/young school children (Dexter \& Hughes, 2011; Meng \& Patty, 1991; Yuill \& Joscelyne, 1988) or more proficient readers/college students (Ausubel, 1960; Corkill, 1992; Glenberg \& Langston, 1992; Wilhite, 1989). Ausubel (1960) advocates the use of advance organisers (e.g., preceding drawings, maps, headlines, and short introductory paragraphs) in teaching reading, and suggests that prior contextual information facilitates the integration of new knowledge from the text with readers' previously acquired knowledge. As readers encounter advance organisers, related prior knowledge stored in long-term memory is activated, which in turn, disambiguates high ambiguity texts and creates a context for readers to encode and comprehend the written materials.

Contextual information not only improves comprehension and recall but also facilitates processing efficiency (Smith \& Swinney, 1992; Wiley \& Rayner, 2000). Smith and Swinney (1992) examined whether context provided by a title had an effect on reading speed. Participants read eight sets of stories either with or without a title. The results showed that, in the title condition, participants produced significantly more textual ideas in free recall tasks 
and showed shorter sentence reading times as compared to the no-title condition. This suggests that a readily available context enables readers to quickly establish a semantic relationship between propositions in the text, resulting in a more interrelated mental representation and thereby speeding reading.

\section{Text comprehension and contextual supports in readers with aphasia}

Reading ability of people with aphasia may be impaired in terms of speed and comprehension accuracy. People with aphasia report that reading becomes time-consuming following the onset of aphasia and that, consequently, they reduce their reading (Kjellén et al., 2017; Knollman-Porter et al., 2015). Compared to typical readers, people with aphasia have significantly longer reading times (e.g., Webb \& Love, 1983; Webster, Morris, et al., 2018), and despite not showing comprehension problems, some do still read at a slower speed (Meteyard, Bruce, Edmundson, \& Oakhill, 2015; Webb \& Love, 1983; Webster, Morris, et al., 2018). In addition to reduced speed, people with aphasia also achieve lower comprehension accuracy (e.g., Nicholas \& Brookshire, 1987; Webb \& Love, 1983; Webster, Morris, et al., 2018). Like typical readers, people with aphasia show greater difficulty in understanding and remembering information that is less important in the text (Meteyard et al., 2015; Webster, Morris, et al., 2018). They also have substantial difficulty in making inferences to maintain text coherence and show poorer performance on questions about inferred ideas than on questions about stated ideas (Meteyard et al., 2015; Nicholas \& Brookshire, 1987; Webster, Morris, et al., 2018).

Given their linguistic and potential wider cognitive processing deficits, one would predict people with aphasia to show worse comprehension at the text level than at the single word and sentence level. However, several studies have reported that people with aphasia have better text comprehension than sentence comprehension in both the spoken (Brookshire \& Nicholas, 1984; Waller \& Darley, 1978) and written (Caplan \& Evans, 1990; Meteyard et 
al., 2015; Stachowiak, Huber, Poeck, \& Kerschensteiner, 1977) modalities. It has therefore been proposed that, as sentences presented in isolation provide limited context, readers/listeners have to rely primarily on grammatical/syntactic knowledge to comprehend them (Brookshire \& Nicholas, 1984; Stachowiak et al., 1977). On the other hand, the repetition and redundancy of information and supporting context available within discourse can facilitate people with aphasia's comprehension (Brookshire \& Nicholas, 1984; Caplan \& Evans, 1990; Stachowiak et al., 1977; Webster, Morris, et al., 2018). Indeed, many individuals with aphasia do indicate a preference for written materials that are topic familiar (Knollman-Porter et al., 2015) and include pictures (Knollman-Porter et al., 2015; Rose, Worrall, Hickson, \& Hoffmann, 2012).

Aphasia-friendly materials use simplified vocabulary and syntax, large print, and increased white space and often include pictorial information (e.g., line drawings, black-andwhite or colour photographs) to support people with aphasia's understanding. Studies of the effectiveness of aphasia-friendly written materials (Brennan, Worrall, \& McKenna, 2005; Rose, Worrall, Hickson, \& Hoffmann, 2011; Wilson \& Read, 2016) have examined the role of pictures in these materials. These studies required participants to read paragraphs adapted from published reading sources and select the best word from four possible options, each illustrated by a picture, to complete the final sentence of each paragraph. None of these studies found that the inclusion of pictures improved comprehension accuracy (Brennan et al., 2005; Rose et al., 2011; Wilson \& Read, 2016) or increased response speed (Rose et al., 2011).

In the aforementioned studies, pictures were used to illustrate a lexical item. Using pictures in this way could potentially benefit understanding of specific words, but it may not be the appropriate method to determine whether the presence of pictures can influence the comprehension of the whole text. Moreover, pictures were presented with texts rather than as 
advance contextual organisers. Studies with typical readers have suggested that, to be helpful, contextual organisers should be presented to the learners/readers in advance (Ausubel, 1960; Meng \& Patty, 1991). The simultaneous presentation of picture and text might distract and cause readers to divert processing to the picture rather than dedicate their whole attention to processing and comprehending texts. Indeed, it could also require extra processing capacity for some people with aphasia to integrate both pictorial and textual information to form a coherent mental representation. Given that cognitive deficits, including working memory (Caspari, Parkinson, LaPointe, \& Katz, 1998; Murray, 2002; Tompkins, Bloise, Timko, \& Baumgaertner, 1994) and attention (Lee \& Sohlberg, 2013; McNeil et al., 1993), are common in people with aphasia, extra processing could adversely impact their comprehension (Waller \& Darley, 1978).

Dietz and colleagues $(2009 ; 2014)$ also investigated the influence of pictorial information on people with aphasia's reading, but using pictures as contextual support for researcher-composed short narratives (rather than as lexical illustrations as in the studies with aphasia-friendly materials). The Dietz et al. studies still focused on comprehension measures (accuracy and/or response speed) only and did not consider whether contextual supports may impact reading speed of people with aphasia. However, unlike the studies discussed above, they did use a more nuanced comprehension assessment targeting both factual and inferential text content. In the 2009 study, seven people of varying aphasia severity and reading ability read narratives that were presented with either two low-context photographs (e.g., a portrait of a person on a plain background), two high-context photographs (e.g., a photograph of fans cheering as they watch a sporting event), or alone. Once participants indicated they had finished reading, both photographs and narrative were removed, and participants responded to nine multiple-choice questions. The results showed that people with aphasia had significantly higher comprehension accuracy in the high-context than in the low-context 
photograph condition. However, while they indicated their preference for texts with photographs, they did not show any significant difference between either photograph condition and the no-context condition. In addition, participants showed significantly longer response times for comprehension questions in the high-context photograph than in the nophotograph condition.

Dietz et al. (2014) extended their investigation to two other types of contextual supports, titles and keywords, in addition to photographs. Seventeen participants with aphasia read four researcher-composed narratives that were presented with either a colour photograph, a short title, a list of keywords, or no support and followed by multiple-choice comprehension questions. The photograph or the title captured the meaning conveyed at the beginning of each story while keywords conveyed important concepts relating to the main story events. Unlike the earlier study which showed photographs during reading only, in this study contextual supports were presented both prior to reading and during reading, and both texts and contextual supports remained available for review during comprehension questions. The results of this study showed that, compared to the no-support condition, none of the contextual supports (including photographs) significantly improved people with aphasia's comprehension, although there was significantly higher accuracy in the photograph than in the keyword condition. In short, the results of both Dietz et al. studies $(2009,2014)$ found no support for their prediction that contextual supports including pictures would benefit people with aphasia's reading. However, once again, both studies presented pictures and texts together, and the finding of slower response speed in the high-context photographs condition suggested that the simultaneous presentation could have required more processing resources for people with aphasia. In addition, neither study reported whether contextual supports had an influence on people with aphasia's comprehension of factual or inferential ideas in the text. Given that people with aphasia show varying difficulty for different types of textual 
information, it is possible that contextual supports may impact their understanding of a specific type of textual information while not having an effect on overall comprehension.

To summarise, none of the previous studies have shown that pictorial information presented alongside texts benefits people with aphasia's comprehension accuracy for texts that were either selected from standardised published sources or created by the researchers. However, there has been no investigation of whether provision of context in advance influences reading in aphasia nor whether context differentially impacts understanding of subtypes of type of textual information. Furthermore, prior research has not yet examined the effect of context on reading speed in aphasia even though slowed reading is a common complaint of many people after acquiring aphasia (Knollman-Porter et al., 2015; Meteyard et al., 2015).

This study therefore examined the influence of advance pictorial context on people with aphasia's (1) reading speed, (2) overall comprehension, and (3) comprehension of different types of textual information, for authentic everyday texts. Specifically, this study addressed the following research questions:

1. Does advance picture context influence people with aphasia's reading speed for everyday texts?

2. Does advance picture context influence people with aphasia's comprehension accuracy for everyday texts?

3. Does advance picture context show a larger effect on people with aphasia's comprehension accuracy of subtypes of textual ideas as classified by their salience and explicitness in everyday texts?

\section{METHOD}

Ethical approval for the present study was obtained from Newcastle University, United Kingdom. 


\section{Participants}

Participants were 29 typical readers (11 men and 18 women aged 51-85 years; see Table 1) and 10 people with aphasia (8 men and 2 women aged 64-76 years; see Tables 1 and 2). All participants reported no history of developmental literacy difficulties (e.g., dyslexia, slow reading acquisition) and had normal or corrected-to-normal vision and hearing ability. Typical readers were University staff or members of a research volunteer pool at Newcastle University, while participants with aphasia were members of a local aphasia support group. Participants with aphasia's time post-stroke ranged from 7 to 36 months and they were diagnosed with aphasia by a speech and language therapist at the time of their participation in the study. Typical readers had years of education ranging from 10 to 17 , with $53.3 \%$ of them having undertaken higher education to degree level (40\% up to a bachelor's degree and $13.3 \%$ up to a master's degree). Participants with aphasia had a range of 11 to 20 years education, with $30 \%$ having undertaken higher education up to degree level (i.e., $20 \%$ up to a bachelor's degree and $10 \%$ up to a doctoral degree).

All participants completed a series of background cognitive tests to provide an overview of cognitive status (see Table 1) and participants with aphasia also completed some language assessments. The cognitive tests included: the Short Recognition Test for Faces (CRSMT-F) and Short Recognition Test for Words (CRSMT-W) from the Camden Memory Tests (Warrington, 1996), Auditory Attention Task from the Birmingham Cognitive Screen (BCoS; Humphreys, Riddoch, Samson, \& Bickerton, 2012), and Modified Wisconsin Card Sorting Task (M-WCST; Schretlen, 2010). The language tests included the Semantic Memory, Spoken Picture Description, Comprehension of Spoken Words, Comprehension of Written words, Comprehension of Spoken Sentences, Comprehension of Written Sentences, and Reading-aloud, all from the Comprehensive Aphasia Test (CAT; Swinburn, Porter, \& Howard, 2004). 
TABLE 1. Summary of participant information.

\begin{tabular}{|c|c|c|c|c|c|}
\hline & \multirow[b]{2}{*}{$\max$} & \multicolumn{2}{|c|}{$\begin{array}{l}\text { adult typical readers } \\
\mathrm{n}=29(11 \mathrm{~m} / 18 \mathrm{f})\end{array}$} & \multicolumn{2}{|c|}{$\begin{array}{l}\text { readers with aphasia } \\
\qquad \mathrm{n}=10(8 \mathrm{~m} / 2 \mathrm{f})\end{array}$} \\
\hline & & range & mean(sd) & range & mean(sd) \\
\hline Age (years) & $\mathrm{n} / \mathrm{a}$ & $51-85$ & $66.4(9.18)$ & $64-76$ & $71.2(4.29)$ \\
\hline Length of education (years) & $\mathrm{n} / \mathrm{a}$ & $10-17$ & $14.3(2.18)$ & $11-20$ & $13.3(2.95)$ \\
\hline Time post-stroke (years) & $\mathrm{n} / \mathrm{a}$ & $\mathrm{n} / \mathrm{a}$ & $\mathrm{n} / \mathrm{a}$ & $0.5-3$ & $2.56(.94)$ \\
\hline M-WCST (standard score) & $\mathrm{n} / \mathrm{a}$ & $62-130$ & $95.7(18.66)$ & $40-110$ & $106(17.34)$ \\
\hline BCoS Auditory Attention Task & 54 & $47-54$ & $53.6(1.33)$ & $41-54$ & $50(5.21)$ \\
\hline CSRMT-F & 25 & $17-25$ & $23.6(1.97)$ & $19-25$ & $23.2(1.93)$ \\
\hline CSRMT-W & 25 & $23-25$ & $24.8(.48)$ & $15-24$ & $21.2(4.07)$ \\
\hline \multicolumn{6}{|l|}{ Comprehensive Aphasia Test* } \\
\hline Spoken picture description & $\mathrm{n} / \mathrm{a}$ & & & $16-42.5$ & $27.7(10.02)$ \\
\hline Semantic memory & 10 & & & $9-10$ & $9.9(.32)$ \\
\hline Comprehension of spoken words & 30 & & & $24-29$ & $26.6(1.77)$ \\
\hline Comprehension of written words & 30 & & & $24-30$ & $28.9(1.91)$ \\
\hline Comprehension of spoken sentences & 32 & & & $15-30$ & $23.5(6.06)$ \\
\hline Comprehension of written sentences & 32 & & & $17-31$ & $23.1(4.36)$ \\
\hline Reading words & 48 & & & $19-48$ & $35.6(10.95)$ \\
\hline Reading complex words & 6 & & & $0-6$ & $3.5(2.5)$ \\
\hline Reading function words & 6 & & & $2-6$ & $5.3(1.33)$ \\
\hline Reading nonwords & 10 & & & $0-10$ & $5.7(3.8)$ \\
\hline
\end{tabular}

Note. m: male; f: female; sd: standard deviation; CRSMT-F and CRSMT-W: Short

Recognition Memory Test for Faces and for Words from the Camden Memory Tests; M-

WCST: Modified Wisconsin Card Sorting Test; *: Only participants with aphasia completed the assessments from the Comprehensive Aphasia Test; All reading assessments are reading aloud. n/a: not applicable; max.: the maximum score for an assessment.

To be included in the study, typical readers could not perform below the normal range on more than one cognitive assessment. Participants with aphasia were not excluded on the basis of their performance on cognitive assessments and showed a range of levels of performance (see Table 2). Most participants with aphasia did not show difficulty understanding spoken or written single words. More than half of them showed difficulty in sentence comprehension and oral reading and also had difficulty in producing connected speech. Although two participants with aphasia scored within the normal range on all CAT sub-tests, this most likely reflects ceiling effects on this task, and all had a current diagnosis of aphasia by a speech and language therapist. 
TABLE 2. Profile of individual participants with aphasia.

\begin{tabular}{|c|c|c|c|c|c|c|c|c|c|c|c|}
\hline Participant ID & $\begin{array}{c}\text { normal } \\
\text { range }\end{array}$ & PA1 & PA2 & PA3 & PA4 & PA5 & PA6 & PA7 & PA8 & PA9 & PA10 \\
\hline Gender & $\mathrm{n} / \mathrm{a}$ & $\mathrm{f}$ & $\mathrm{m}$ & $\mathrm{m}$ & $\mathrm{m}$ & $\mathrm{f}$ & $\mathrm{m}$ & $\mathrm{m}$ & $\mathrm{m}$ & $\mathrm{m}$ & $\mathrm{m}$ \\
\hline Age (years) & $\mathrm{n} / \mathrm{a}$ & 69 & 67 & 74 & 76 & 74 & 75 & 69 & 76 & 68 & 64 \\
\hline Years of education & $\mathrm{n} / \mathrm{a}$ & 11 & 12 & 13 & 13 & 16 & 11 & 11 & 20 & 15 & 11 \\
\hline Time post-stroke (years) & $\mathrm{n} / \mathrm{a}$ & 1 & 3 & 3 & .58 & 3 & 3 & 3 & 3 & 3 & 3 \\
\hline M-WCST & $\mathrm{n} / \mathrm{a}$ & A & A & L.A & A & $\mathrm{S}$ & A & $\mathrm{S}$ & $\mathrm{n} / \mathrm{p}$ & $\mathrm{n} / \mathrm{p}$ & L.A \\
\hline BCoS Auditory Attention Task & $50 *$ & 53 & 54 & 53 & 54 & 53 & 49 & 41 & $\mathrm{n} / \mathrm{p}$ & $\mathrm{n} / \mathrm{p}$ & 43 \\
\hline CSRMT for Faces & 19 & 24 & 24 & 23 & 25 & 25 & 23 & 25 & 23 & 19 & 21 \\
\hline CSRMT for Words & 19 & 25 & 25 & 22 & 24 & 25 & 23 & 21 & 17 & 15 & 15 \\
\hline Spoken picture description & $33-87$ & 39.5 & 41.5 & 27.5 & 28 & 42.5 & 23 & 21 & 16 & 19 & 19 \\
\hline Semantic memory & 10 & 10 & 10 & 10 & 10 & 10 & 10 & 10 & 10 & 9 & 10 \\
\hline Comprehension of spoken words & $25-30$ & 29 & 29 & 28 & 26 & 24 & 26 & 26 & 27 & 27 & 24 \\
\hline Comprehension of written words & $27-30$ & 30 & 30 & 30 & 30 & 30 & 28 & 29 & 30 & 24 & 28 \\
\hline Comprehension of spoken sentences & $26-32$ & 30 & 30 & 31 & 23 & 15 & 22 & 19 & 28 & 22 & 15 \\
\hline Comprehension of written sentences & $24-32$ & 25 & 31 & 29 & 20 & 25 & 22 & 21 & 20 & 17 & 21 \\
\hline Reading words & $44-48$ & 48 & 45 & 46 & 47 & 33 & 23 & 26 & 28 & 43 & 19 \\
\hline Reading complex words & $5-6$ & 6 & 5 & 6 & 6 & 1 & 2 & 2 & 0 & 6 & 1 \\
\hline Reading function words & $4-6$ & 6 & 6 & 6 & 6 & 5 & 6 & 6 & 4 & 6 & 2 \\
\hline Reading nonwords & $6-10$ & 10 & 10 & 6 & 9 & 7 & 3 & 0 & 0 & 8 & 4 \\
\hline
\end{tabular}

Note. Participant IDs appear in the ascending order of the number of tasks they performed outside normal range or did not perform. M-WCST: Modified Wisconsin Cart Sorting Test; CSRMT for Faces and CSRMT for Words: Short Memory Recognition Test for Faces/Words from the Camden Memory Tests; A: average; L.A: low average; S: Superior; n/a: not applicable; n/p: PA8 and PA9 declined to perform these tasks; * For the BCOS Auditory Attention Task, the cut-off score of the age range 64-74 is 50; bold italics digits indicate scores outside normal range.

\section{Materials}

\section{Reading texts}

The study included 45 texts which were short online news articles, written for older children but appropriate for adults, from an online British news website (BBC Newsround, https://www.bbc.co.uk/newsround). The texts represented a wide range of topics in order to reduce the influence of participant interest and knowledge. As the original texts varied in length and word use and included some information that required specific knowledge for the 
reader to understand, they were minimally but systematically edited (e.g., removing slang and colloquial language, reducing direct speech sentences, replacing geographically specific information, replacing difficult or low-frequency proper nouns and foreign proper names, e.g., Suryia changed to Suzi).

The selected texts had various readability grades as measured by the Dale-Chall formula (Chall \& Dale, 1995; Dale \& Chall, 1948). The Dale-Chall formula takes into account both lexical and syntactic complexity by considering not only sentence length but also vocabulary size, noting the percentage of unfamiliar words (i.e., words that are not in the list of 3000 words known in reading by at least 80 percent of the children in Grade 5 in the American school system). The Dale-Chall scores of the selected texts were in the range 5.0-7.9. Accordingly, these texts should be easily understood by average readers from $5^{\text {th }}-10^{\text {th }}$ US school grades (aged 10 to 14 years).

The texts were divided into three sets of 15 texts each and matched for: number of words and sentences, Dale-Chall scores, Passage Dependency Index (see the section about comprehension questions), and rating of picture informativeness (see the section about pictures) (see Table 3).

TABLE 3. Sets of texts.

\begin{tabular}{lccccc}
\hline \multicolumn{1}{c}{ Matching criteria } & SET A & SET B & SET C & \multicolumn{2}{c}{$\begin{array}{c}\text { Set comparison - } \\
\text { ANOVA }\end{array}$} \\
\hline & mean (sd) & mean (sd) & mean (sd) & F(2, 42) & $\mathrm{p}$ \\
\hline Number of words & 132.25 & 132.59 & 132.15 & .6 & .551 \\
& $(11.73)$ & $(11.74)$ & $(11.8)$ & & \\
Number of sentences & $7.18(.98)$ & $7.2(.98)$ & $7.18(.98)$ & .57 & .558 \\
Dale-Chall Score & $6.93(.64)$ & $6.83(.69)$ & $6.92(.59)$ & .04 & .961 \\
Passage Dependency Index & $.56(.09)$ & $.56(.09)$ & $.57(.09)$ & .01 & .987 \\
Picture informativeness & $2.85(.78)$ & $2.84(.77)$ & $2.85(.76)$ & .03 & .966 \\
\hline
\end{tabular}

Note. sd: standard deviation

Comprehension questions 
For each text, four comprehension questions were developed to probe textual information differing in salience and explicitness, assessing the understanding of a stated main idea, a stated detail, an implied main idea, and an implied detail. The question used multiple-choice sentence completion format to avoid any confound from the spoken production difficulties that are prevalent in people with aphasia. The definitions of the four types of textual information (see Table 4) were closely based on the definitions in Brookshire and Nicholas (1993) and Webster and colleagues (2018). Like Webster and colleagues (2018), but in contrast to Brookshire and Nicholas (1993), stated information could appear in the questions in the same wording as in the text or could be paraphrased and lexical synonyms were considered stated information rather than inferred information.

Each question had four options, including one target answer and three distractors which were all plausible but incorrect. One distractor included information which was completely unrelated to the content of the text; other distractors consisted of a mix of information from the text and unrelated or inaccurate information. Both questions and answer choices avoided complex grammatical structures (e.g., embedded clauses and passive clauses) where possible, and answer choices for each question were of a similar length and grammatical structure.

As texts came from an authentic source, the generation of questions attempted to ensure that the target answer could only be answered by drawing primarily on information in the texts rather than relying on background knowledge. An online survey was used to consider the familiarity of the texts and the Passage Dependency Index of comprehension questions for each text. The Passage Dependency Index was calculated, using the formula (Tuinman, 1974): 1 - (mean proportion of the questions correctly answered without reading the text to which questions refer/mean proportion of the questions correctly answered with the reading text to which questions refer). 
TABLE 4. Definition of types of textual information.

\begin{tabular}{ll}
\hline \multicolumn{1}{c}{ Types of textual information } & \multicolumn{1}{c}{ Definition } \\
\hline Stated Main Ideas & $\begin{array}{l}\text { Ideas that were directly stated and repeated and/or } \\
\text { elaborated in the text }\end{array}$ \\
Implied Main Ideas & $\begin{array}{l}\text { Ideas that were repeated and/or elaborated, requiring } \\
\text { inferences across sentences or with world knowledge }\end{array}$ \\
Stated Details & $\begin{array}{l}\text { Ideas that were stated directly and not repeated or } \\
\text { elaborated in the text }\end{array}$ \\
Implied Details & $\begin{array}{l}\text { Ideas that were not stated directly and not repeated or } \\
\text { elaborated, requiring inferences within one sentence or } \\
\text { with world knowledge }\end{array}$ \\
\hline
\end{tabular}

Forty-eight native English speakers (22 men and 26 women) first answered all comprehension questions without reading the related texts and then had to respond to the same questions after reading the texts. Finally, they were asked whether they had ever come across the text before (YES, MAYBE, or NO). Over $80 \%$ of participants reported to have never encountered the texts and the Passage Dependency Index of the texts ranged from .4 to .74. There appear to be no standard values for what is considered as acceptable passage dependency indices (Nicholas \& Brookshire, 1987; Thomas \& Jackson, 1997) but some researchers have suggested .45 or higher is adequate (Hanna, Schell, \& Schreiner, 1977; Thomas \& Jackson, 1997); 39 of our texts met this requirement. The 6 remaining texts had values above .4 but below .45 and were rated as highly unfamiliar, suggesting that people generally could not respond correctly to comprehension questions without reference to the texts.

\section{Pictures}

In the original source, all forty-five selected texts were accompanied by a picture (colour photograph). Five of the original pictures were judged by the researchers to be of low visual quality and replaced by new pictures selected from Google Images, 
https://images.google.com/. Via an online survey, the degree to which pictures were informative about their accompanying texts was rated on a seven-point Likert scale (0-not informative at all to 6-highly informative) by 23 native English speakers ( 6 men and 17 women). Twenty-two pictures had a mean rating less than 2.7 , indicating that they provided a little information for understanding the text (e.g., a picture of a squirrel in isolation, accompanying a text about a project helping squirrels find food). The remaining 23 pictures had a mean rating from 3 to 4.46, indicating that they were moderately informative for understanding their accompanying texts. These pictures either presented a specific type of object or animal (e.g., a picture of a dog sniffing a bomb, accompanying a text about honouring an army dog) or depicted detail appearing in the text (e.g., rescuers helping a sheep stuck on a cliff). None of the pictures were rated as highly informative (i.e., rating mean above 5). The level of picture informativeness was counterbalanced across the three sets of the selected texts (see Table 3 above).

In addition to the 45 pictures related to the text context as described above, we also included 45 unrelated pictures as fillers. The unrelated pictures were colour photographs selected from Google Images, https://images.google.com/, and judged by the researchers as unrelated if they did not show any nouns appearing in the text. These fillers were not included in the primary analysis.

\section{Procedures}

The background assessments and the experimental task in total lasted up to one and a half hours for typical readers and three hours for participants with aphasia. Participants chose to complete the study over one visit with short breaks or on different days; 21 typical readers completed in one visit, eight over two visits within two weeks, all participants with aphasia were seen over three different days within a month. 
The reading materials were presented on a touch-screen laptop using DMDX experimental software (Forster \& Forster, 2003). After signing a consent form and answering demographic background questions, participants were seated comfortably in front of the laptop screen and given the instructions for the reading task (see below) in both written and oral form. The instructions required participants to look at the picture if one appeared, read each text silently and carefully, and answer comprehension questions following each text.

For each trial, participants first saw a fixation point (an asterisk) in the centre of the laptop screen and pressed the spacebar to move on. Participants would then see a text immediately or see a picture first. When they had finished viewing the picture, they pressed the spacebar to move on and saw an asterisk; they pressed the spacebar to advance to a text and pressed again to indicate that they finished reading. An asterisk appeared once again, and participants pressed the spacebar to advance to comprehension questions. To answer a question, participants touched the region of the screen where the option they wanted to choose was located. Reading time was measured from when a text was shown on the screen to when participants pressed the spacebar to indicate they had finished reading (participants were told to press the spacebar as soon as they had finished reading a text).

Twelve pseudo-randomized versions of trial order were created, with no more than two consecutive occurrences of same context condition in each version: four versions with Set A texts appearing with related pictures, Set B with unrelated pictures and Set C with no pictures; four versions with Set A appearing with unrelated pictures, Set B with no pictures and Set $\mathrm{C}$ with related pictures, and four versions with Set A with no pictures, Set B with related pictures and Set $\mathrm{C}$ with unrelated pictures. Participants were randomly assigned a trial order. There was one practice trial at the start of each section of the reading task; three participants with aphasia needed extra practice, while none of the typical readers did.

\section{Analysis}


Reading times were $\log _{10}$-transformed to reduce skewedness, and data points above 2.5 standard deviations from the mean of the distribution were removed (Baayen \& Milin, 2010), resulting in loss of 16 data points. We used the lme4 package (Bates, Mächler, Bolker, \& Walker, 2015) in R (R Core Team, 2018) to examine the effect of advance picture context on reading times. We computed a linear mixed-effects model which included group (typical, aphasia), advance picture context ${ }^{1}$ (related picture, no picture), and their interaction as fixed effects and participant and text as random effects. Similarly, for comprehension accuracy as a binary dependent variable, we computed a logit linear mixed-effects model which included group, advance picture context, salience (main idea, detail), explicitness (stated, implied), and two-way, three-way, four-way interactions between the four factors as fixed effects and participant and question as random effects. For both models, all predictors of interests were deviation coded $(-0.5,0.5)$ (i.e., the mean of each level was compared with the grand mean).

\section{RESULTS}

\section{Reading time}

As demonstrated in Figure 1, typical readers had significantly shorter reading times $(\mathrm{M}=41.35$ seconds, $\mathrm{SD}=17.12)$ than readers with aphasia $(\mathrm{M}=79.98$ seconds, $\mathrm{SD}=33.47), \mathrm{b}=-$ $.29, \mathrm{SE}=.055, \mathrm{t}=-5.39, \mathrm{p}<.001$, and both groups showed significantly shorter reading times in the picture (typical: $\mathrm{M}=40.45$ seconds, $\mathrm{SD}=17.41$; aphasia: $\mathrm{m}=78.59$ seconds, $\mathrm{sd}=36.77$ ) than in no-picture (typical: $\mathrm{M}=42.23$ seconds, $\mathrm{SD}=16.79$; aphasia: $\mathrm{M}=81.45$ seconds, $\mathrm{SD}=33.20$ ) condition, $\mathrm{b}=.027, \mathrm{SE}=.006, \mathrm{t}=4.54, \mathrm{p}<.001$. There was, however, no interaction between group and context, $\mathrm{b}=-.004, \mathrm{SE}=.012, \mathrm{t}=-.34, \mathrm{p}=.735$, suggesting a similar effect of picture context across the two participant groups.

\footnotetext{
${ }^{1}$ The unrelated picture fillers were not included in any analyses presented here. Paired t-tests did not show a significant difference in reading times or comprehension accuracy between the unrelated filler and no-picture conditions.
} 
As advance picture context had an effect on reading times at the group level, we computed non-parametric Mann-Whitney U tests to examine the effect at the individual level for readers with aphasia. Eight of the 10 participants with aphasia had numerically faster reading times for the picture than for no-picture condition (see Figure 2), with one participant (PA8) having a significant reading time difference between the picture and no-picture condition $(\mathrm{W}=81, \mathrm{P}=.036)$.

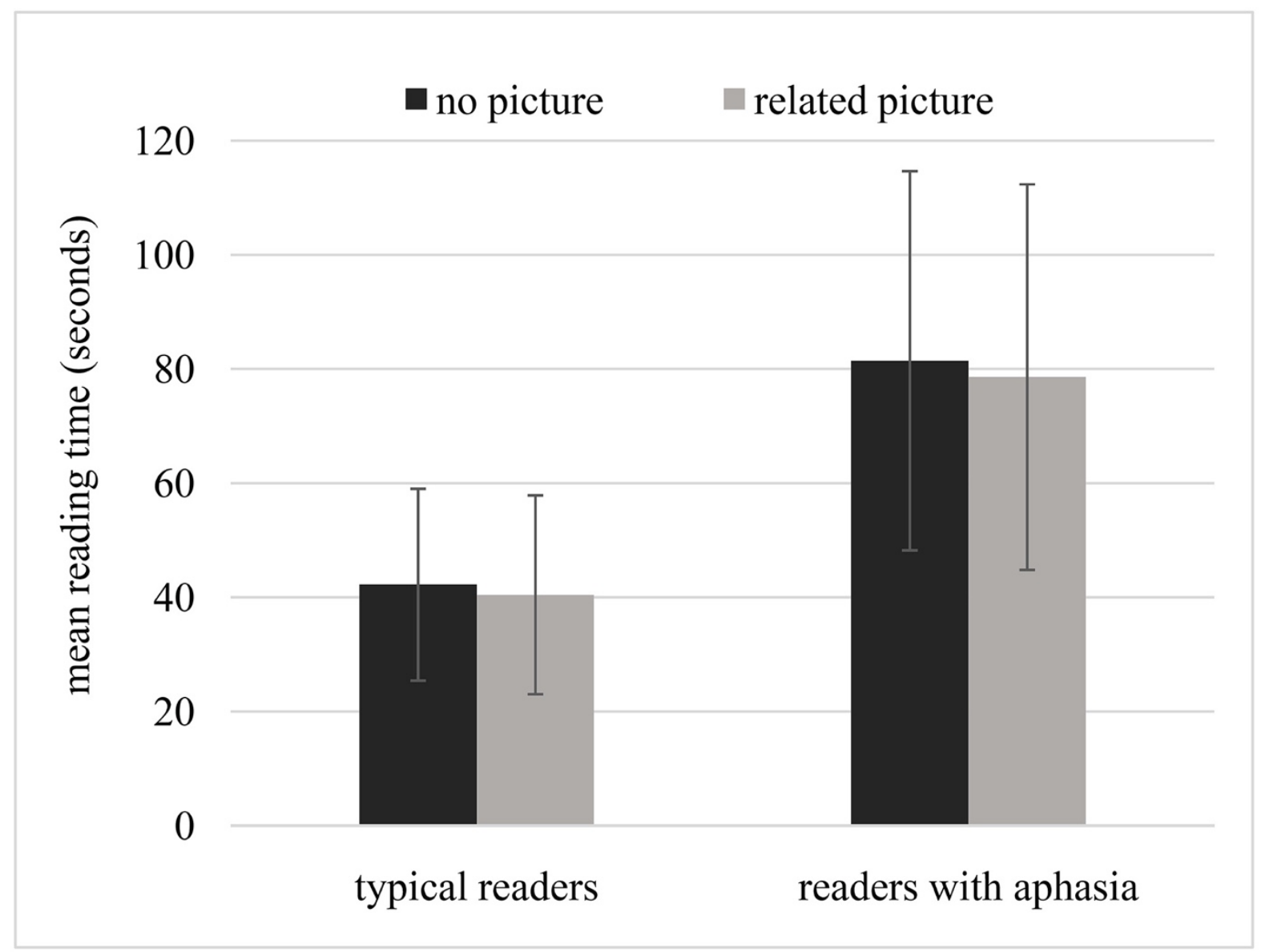

Figure 1 Mean reading times (in seconds) of typical readers and readers with aphasia in the picture and no-picture conditions. Error bars show standard deviations. 


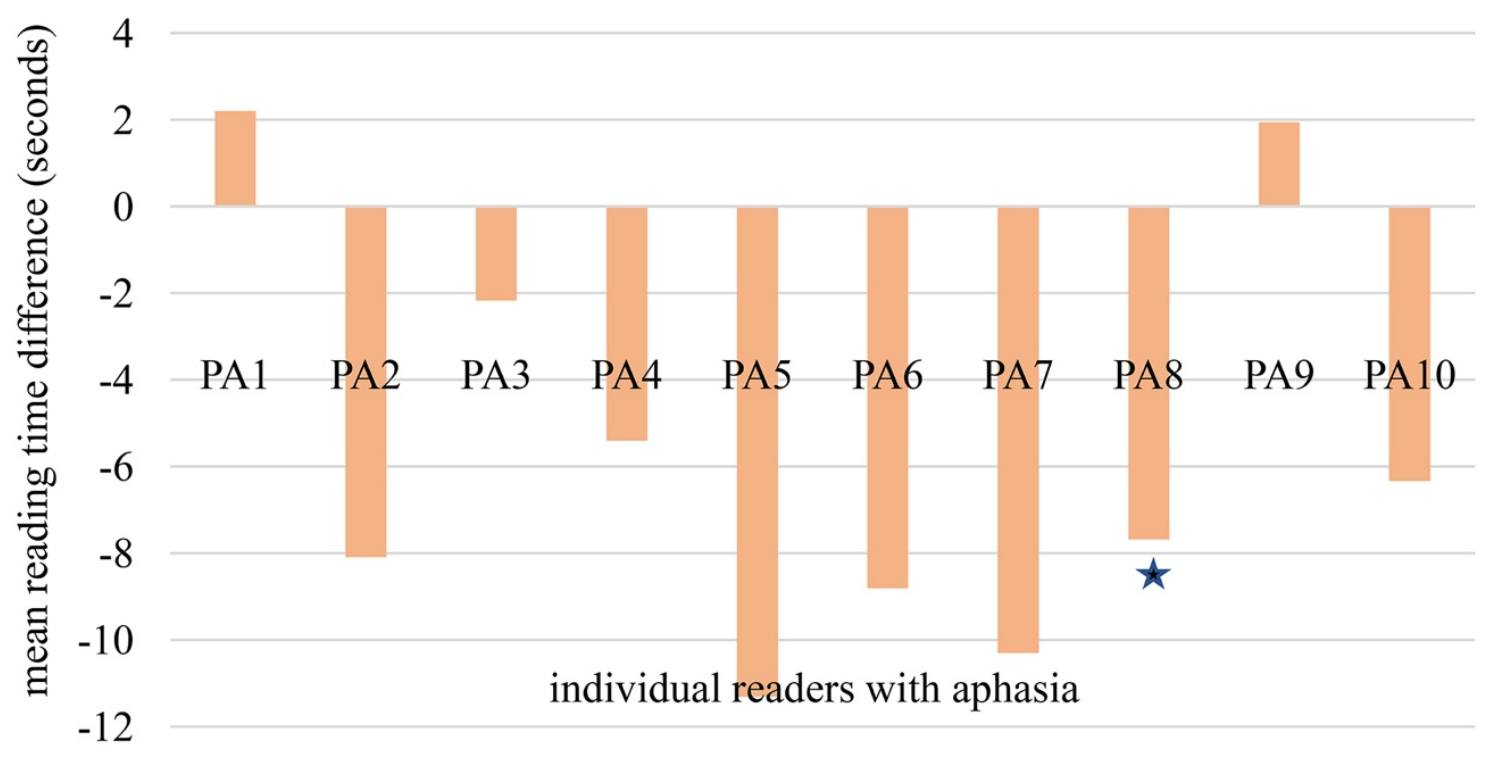

Figure 2 Individual participants' difference in mean reading time (in seconds) between the picture and no-picture conditions. A negative number indicates a faster reading speed relative to the no-picture condition. * PA8 showed a significant reading time difference between the picture and no-picture condition.

\section{Comprehension accuracy}

Table 5 summarises the results of the analysis of comprehension accuracy. There was no significant effect of picture context indicating that the two groups had comparable accuracy for each question type between the picture and no-picture conditions (see Figure 3). There was a main effect of group reflecting the fact that, typical readers $(M=107.34 / 120, S D=6.24)$ had higher comprehension accuracy than did readers with aphasia $(\mathrm{M}=81.4 / 120, \mathrm{SD}=24.64)$. There were also main effects of salience indicating that, taken together, typical readers and readers with aphasia responded more accurately to questions about main ideas $(M=52.62 / 60$, $\mathrm{SD}=8.48)$ than to questions about details $(\mathrm{M}=48.08 / 60, \mathrm{SD}=9.25)$, and of explicitness showing that they responded more accurately to questions about stated ideas $(M=51.61 / 60$, $\mathrm{SD}=8.24)$ than implied ideas $(\mathrm{M}=49.08 / 60, \mathrm{SD}=9.51)$. There was no interaction between the factors included in the model, indicating that advance picture context neither had a larger 
effect on accuracy for readers with aphasia than typical readers, nor for a particular type of textual information than the other (see Figure 4).

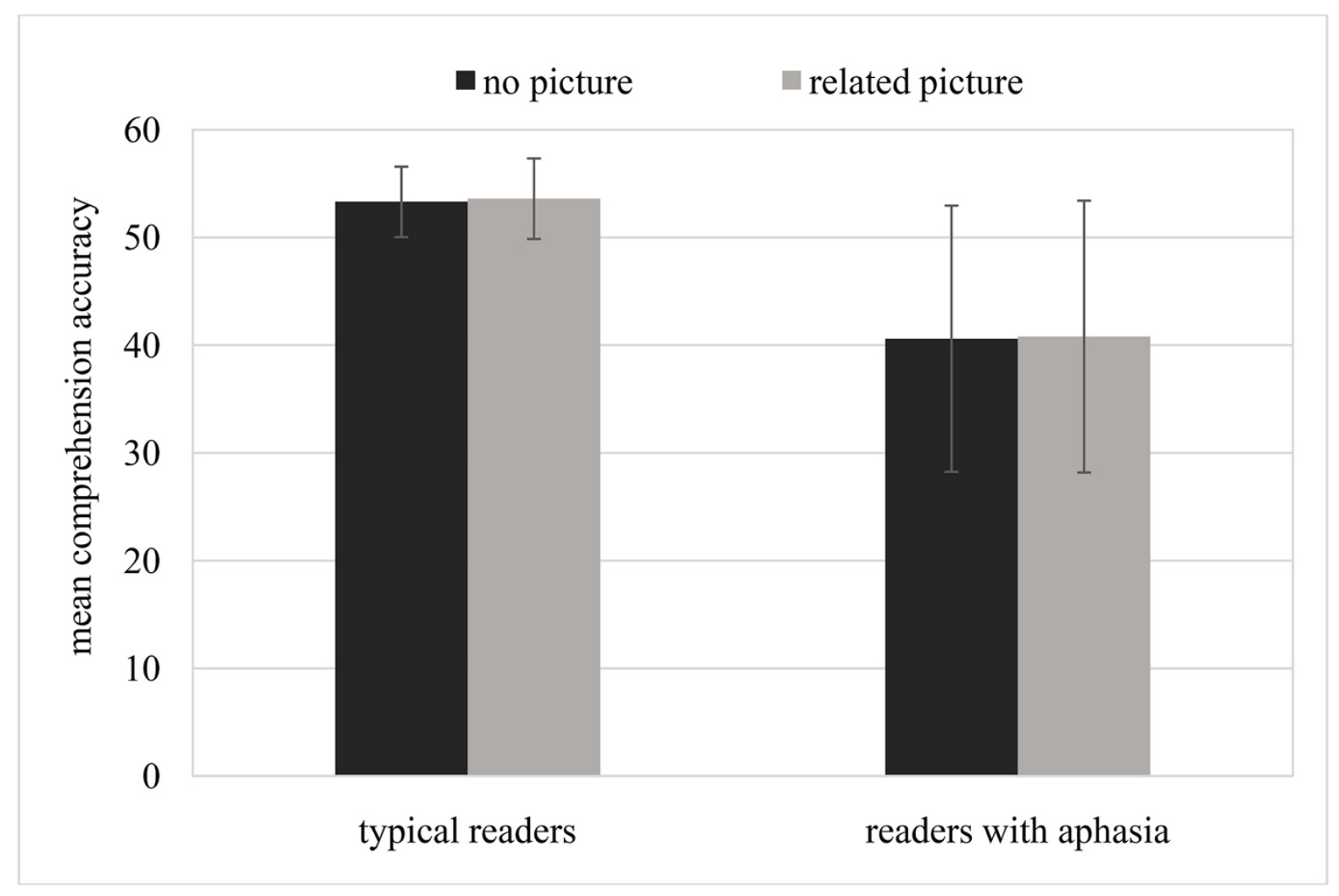

Figure 3 Comprehension accuracy of typical readers and readers with aphasia in the picture and no-picture conditions. The maximum number of correct responses per condition was 60. Error bars show standard deviations. 


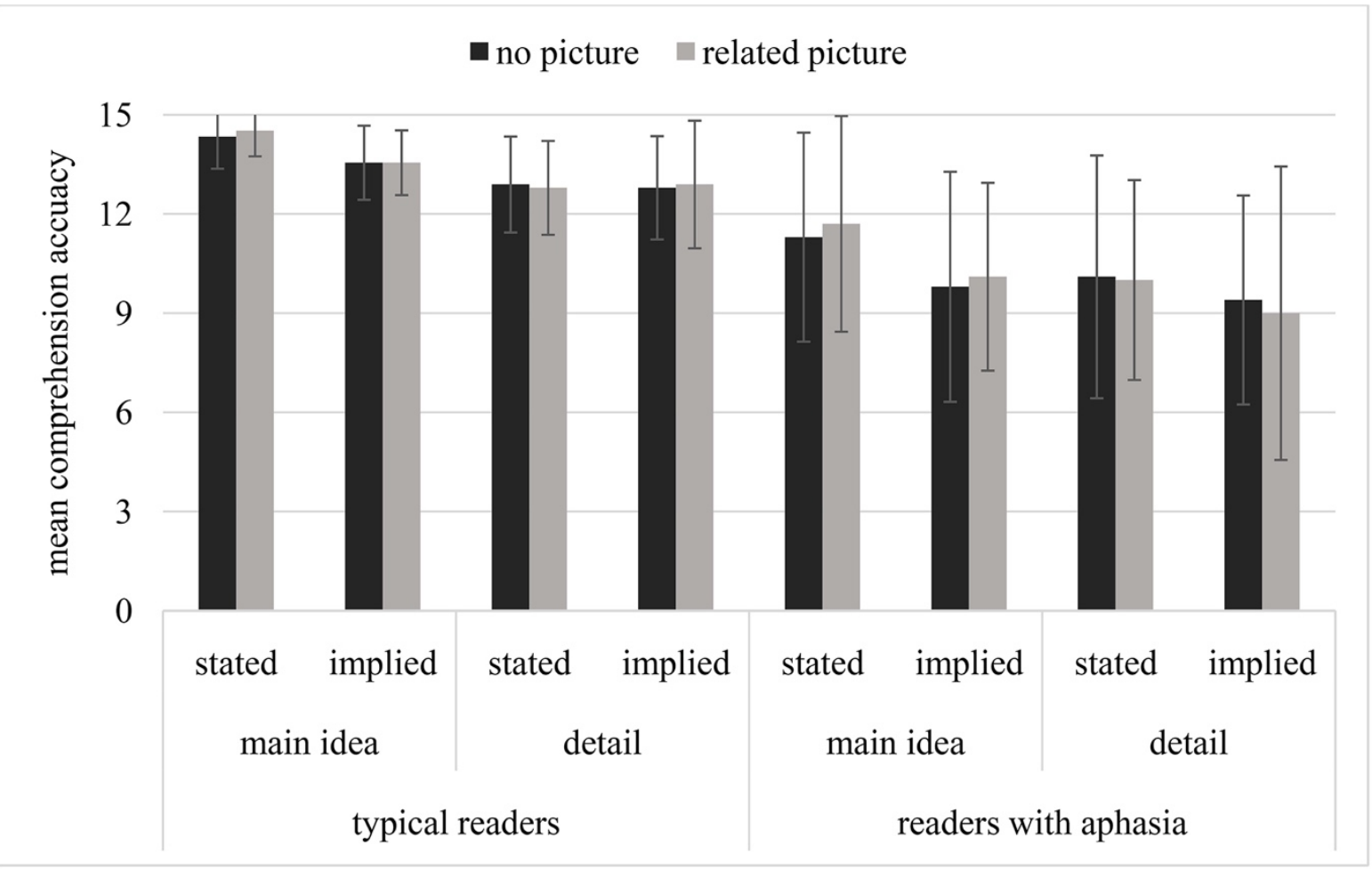

Figure 4 Comprehension accuracy of typical readers and readers with aphasia for each question type in the picture and no-picture conditions. The maximum number of correct responses per question type per condition was 15. Error bars show standard deviations.

TABLE 5. Effects of picture context on comprehension accuracy.

\begin{tabular}{lcccc}
\hline Fixed effects & $\mathrm{b}$ & $\mathrm{SE}$ & $\mathrm{z}$ & $\mathrm{p}$ \\
\hline intercept & -1.96 & .18 & -10.84 & $<.001$ \\
group & .87 & .16 & -5.423 & $<.001$ \\
picture context & .03 & .05 & -.57 & .595 \\
salience & .38 & .09 & -4.01 & $<.001$ \\
explicitness & -.24 & .09 & -2.53 & $\mathbf{. 0 1 1}$ \\
salience:explicitness & -.18 & .09 & -1.87 & .059 \\
group:picture context & -.13 & .05 & -.26 & .795 \\
group:salience & -.14 & .05 & -1.85 & .063 \\
group:explicitness & .01 & .05 & -.3 & .763 \\
group:salience:explicitness & -.08 & .05 & -1.66 & .096 \\
picture context:salience & -.04 & .05 & -.99 & .319 \\
picture context:explicitness & .03 & .05 & .54 & .588 \\
picture context:salience: explicitness & -.08 & .05 & -.433 & .664 \\
group:picture context:salience & -.008 & .05 & -.16 & .326 \\
group:picture context:explicitness & .02 & .05 & -.04 & .664 \\
group:picture context:salience:explicitness & .04 & .05 & .75 & .452 \\
\hline
\end{tabular}

Note. Bold $\mathrm{p}$ values indicate significant results. Salience distinguishes main ideas and details in the text and explicitness distinguishes stated and implied ideas. 


\section{DISCUSSION}

This study investigated the influence of advance context provided by pictures on text reading in people with aphasia. Unlike previous studies, we used naturalistic everyday texts rather than researcher-made texts or texts from standardised language batteries to study contextual influences on reading at the text level in aphasia. This was also the first study to consider the effects of pictures as advance contextual supports and consider the effects on reading speed of people with aphasia. Our discussion will be presented for each of our research questions in turn.

\section{Does advance picture context influence people with aphasia's reading speed for everyday texts?}

Our results showed an effect of advance picture context on reading speed, with both typical readers and readers with aphasia showing shorter reading times when pictures were available, and, importantly, without a speed-accuracy trade-off for comprehension. This finding complements previous studies with typical readers demonstrating faster reading speed for texts with high ambiguity when contextual supports are available (Smith \& Swinney, 1992). The effect of advance picture context on reading speed appears to support the assumption about the role of context in text comprehension under Kintsch's (1988) Construction-Integration model. When context has been provided, a clear semantic relation between propositions is already established and so, less processing is required, thus speeding reading. In addition, although the effect of context at word and sentence level was beyond the scope of the present study, in typical readers context can speed word (e.g., Wiley \& Rayner, 2000) and sentence (e.g., Smith \& Swinney, 1992; Wiley \& Rayner, 2000) processing, which in turn could lead to faster processing at the text level.

When a picture context was available before reading, readers with aphasia and typical readers showed an average increase of $2.96(\mathrm{SD}=33.47)$ and $1.78(\mathrm{SD}=17.12)$ seconds 
respectively in their reading speed, compared to when there was no advance context.

However, there was no significant interaction between advance picture context and group, suggesting that both readers with and without language deficits benefitted from context to a similar extent in terms of reading speed. These results, however, should be considered with caution, as this study included a small sample of only 10 people with aphasia and 4 of whom, despite having a current diagnosis of aphasia, generally showed performance similar to that of the typical readers on the cognitive assessments used. It is, nevertheless, noteworthy that the majority of the individual participants with aphasia had numerically faster reading speed for the texts preceded by a picture.

This study used a broad measure of reading speed which did not allow for separating the re-reading time from the total reading time. Re-reading might indicate reprocessing/reanalysis and integration processes in text comprehension, and people with aphasia's slowed reading might result from their difficulty in integrating information across texts and need for more reprocessing. Eye tracking, a commonly used method for investigating real-time reading in typical readers (for review, see Rayner, 2009), has been used to study the role of context in text comprehension (e.g., Rayner, Pacht, \& Duffy, 1994; Wiley \& Rayner, 2000). Wiley and Rayner (2000), for example, found that prior context resulted in typical readers spending less time regressing back to previous text segments and making shorter fixations on the final word of a sentence. Future research could potentially use eye tracking to determine whether context reduces reprocessing for people with aphasia to a greater extent than for typical readers.

\section{Does advance picture context influence people with aphasia's comprehension accuracy for everyday texts?}

Advance picture context did not significantly improve comprehension accuracy of everyday texts in typical readers or readers with aphasia. This contrasts with previous 
findings where typical readers showed significantly higher accuracy when they were provided with contextual information in advance (Ausubel, 1960; Bransford \& Johnson, 1972; Smith \& Swinney, 1992; Wiley \& Rayner, 2000). This could be because texts in previous research were often longer and/or more complex (e.g., learning materials) or ambiguous (e.g., Bransford and Johnson, 1972). Texts in our study were only 110-150 words long and written at grade levels 6-7 and below (Chall \& Dale, 1995; Dale \& Chall, 1948) and thus, were relatively simple. Coupled with this, based on their high educational level, the typical readers in our study were likely to be highly skilled readers. This was also confirmed by their close to ceiling comprehension accuracy (approximately $90 \%$ correct), which left little room for improvement.

Readers with aphasia had lower overall accuracy than typical readers, however, their comprehension accuracy also did not benefit from the provision of picture context. This finding is consistent with the evidence about the lack of benefit from pictures on people with aphasia's accuracy in studies of picture inclusion in aphasia-friendly materials (Brennan et al., 2005; Rose et al., 2011; Wilson \& Read, 2016) and from the Dietz et al. (2009, 2014) studies of photographic contextual supports. However, in our study, it is possible that comprehension accuracy of participants with aphasia might have improved if the pictures had been presented not only in advance but also during reading. Advance provision of pictures (e.g., Bransford \& Johnson, 1972; Eitel, Scheiter, Schüler, Nyström, \& Holmqvist, 2013) and concurrent presentation of text and picture (e.g., Glenberg \& Langston, 1992; Schweppe, Eitel, \& Rummer, 2015) was found to facilitate the understanding of texts in adult typical readers. A brief preview of pictures can allow readers to extract a global spatial structure of the picture which will be used as mental scaffold when reading a subsequent text (Eitel et al., 2013). In contrast, the mutual presence of picture and text can allow readers to go back and reprocess and integrate pictorial information with textual information into a comprehensive 
mental representation (Eitel et al., 2013). Conversely, simultaneous presentation of text and picture may be cognitively challenging for many people with aphasia as it requires dual processing of multi-modality materials and construction of a mental model from two different sources. Continued research is therefore required to examine if different temporal presentation of pictures affects the extent to which people with aphasia's comprehension of everyday texts is improved. This can be particularly meaningful as people increasingly read texts from online sources where they can have a brief view of pictures often shown in an eyecatching manner before seeing texts and can return to review pictures at any time while reading.

As the design of the study included fillers (i.e., unrelated pictures), one might argue there was a possibility that participants deliberately ignored all the pictures as they were often unhelpful. If so, this, in turn could have prevented beneficial effects of related pictures on comprehension accuracy. However, we can exclude this possibility because participants showed a speed advantage for the related picture condition and, consequently, they must have processed the pictures. It is, nevertheless, possible that the effect would have been even bigger if there were no unrelated fillers.

\section{Does advance picture context show a larger effect on people with aphasia's comprehension accuracy of subtypes of textual ideas, classified by salience and explicitness?}

The results of this study showed that adult typical readers and people with aphasia had a significantly better understanding of main ideas than of details and of stated ideas than implied ideas in everyday texts. The findings align with the previous findings in the literature on typical readers (e.g., McKoon \& Keenan, 1981) and extend similar findings with researcher-made texts (e.g., Webster, Morris, et al., 2018) or texts from standardised language batteries (e.g., Meteyard et al., 2015; Nicholas \& Brookshire, 1987) in the aphasia 
literature. These results suggest that the memory for propositions in the text and establishment of coherence between propositions utilises similar mechanisms in readers with and without language impairments.

The finding of an effect of salience (main ideas vs details) supports the assumptions of the Construction-Integration theory (Kintsch, 1988) that propositions are organised in a hierarchical order relative to their importance/salience in the text. The memory representation of propositions starts with more salient information and ends with supporting propositions (McKoon, 1977). Hence, the retrieval of salient propositions is more accurate. In addition, the establishment of semantic relations between propositions requires readers to not only recognise their importance but also to generate inferences in order to construct a coherent link between propositions. Thus, compared to comprehending information directly stated in the text, making inferences requires additional processing, which results in implicit information being recognised/recalled at less accurately, as confirmed by the effect of explicitness of textual information in our data.

We did not find a significant interaction between advance picture context and either salience or explicitness. This appears to contradict the evidence about a greater facilitation of prior knowledge, another type of discourse context, for important ideas than peripheral ideas and for implied details than for stated details in typical readers (e.g., Johnston, 1984; Pearson et al., 1979). However, these previous studies were carried out with young children (developing readers) who either had high or low prior knowledge related to the topic of experimental texts. In contrast, in this study, prior context was manipulated via advance pictorial organisers, and most participants were older adults with a high level of education who were likely skilled readers, and texts were intentionally chosen to cover a wide range of topics, with event-, time-, or place-specific references being removed to minimize participants' use of related prior knowledge (outside the experimental manipulation). The 
absence of an interaction between context and type of textual information is a new finding in the aphasia literature as prior research has focused on general comprehension.

\section{Clinical implications}

Our results have some important implications for both assessment and treatment of reading in aphasia. As our results differed from those where authors used researcher-made or standardised texts, we recommend that the assessment of reading should incorporate authentic reading materials that are encountered in daily life rather than only using decontextualised texts and consider both reading speed and accuracy. In addition, our results suggested that, like typical readers, people with aphasia are more accurate when reading main ideas compared to details and stated ideas compared to implied ideas. Consequently, to better understand people with aphasia' reading difficulty/ability, we need to use assessments that capture the different purposes and goals of reading (e.g., assessments targeting main idea comprehension or details or both).

Reading speed is typically slowed in people with aphasia but often neglected within treatment (Meteyard et al., 2015; Webb \& Love, 1983; Webster, Morris, et al., 2018). Our finding that providing pictures before reading shortened reading times suggests that advance pictorial organisers may be helpful for improving reading speed in people with aphasia. As many everyday written texts such as news articles in print or online include pictures, therapeutic approaches can make use of real-life reading materials and encourage and support people with aphasia to actively and effectively use pictures where available (e.g., carefully reviewing pictures before reading, incorporating information gained from the picture during reading). Indeed, case studies (e.g., Webster et al., 2013) have shown that training participants with aphasia to employ comprehension strategies such as identifying main topics and using advance organisers in reading resulted in improved comprehension accuracy. 
In summary, our study has provided further insights into how people with aphasia read naturalistic everyday texts, with a focus on the influence of provision of advance picture context on their reading. The findings suggest that, as for adult typical readers, advance picture context benefits people with aphasia in terms of reading speed for everyday texts but seems not to affect their comprehension accuracy. In addition, both readers with and without language deficits show similar sensitivity to different types of information in the text, resulting in their better comprehension for salient than peripheral information and for stated than implied information. Our findings should encourage the incorporation of authentic reading materials and activities in assessment and treatment of reading at the text level in aphasia and promote therapeutic approaches developing more effective use of advance pictorial organisers in people with aphasia to increase their reading efficiency and ultimately, their confidence and pleasure in their daily reading.

\section{Acknowledgements}

This work was supported by the European Commission's Erasmus Mundus Fellowship Programme for the International Doctorate for Experimental Approaches to Language and Brain (IDEALAB) under Grant number 2015-1603/001-001-EMJD to the first author. The authors would like to thank all of the participants for taking part in the study and the individuals and organizations who assisted with recruitment to the study.

\section{Disclosure statement}

The authors reported no potential conflict of interest.

\section{References}

Ausubel, D. P. (1960). The use of advance organizers in the learning and retention of meaningful verbal material. Journal of Educational Psychology, 51(5), 267-272. 
https://doi.org/10.1037/h0046669

Baayen, R. H., \& Milin, P. (2010). Analysing reaction times. International Journal of Psychological Research, 3(2), 12-28.

https://doi.org/https://doi.org/10.21500/20112084.807

Bates, D., Mächler, M., Bolker, B. M., \& Walker, S. C. (2015). Fitting linear mixed-effects models using lme4. Journal of Statistical Software, 67(1), 1-48. https://doi.org/10.18637/jss.v067.i01

Bransford, J. D., \& Franks, J. J. (1971). The abstraction of linguistic ideas. Cognitive Psychology, 2(4), 331-350. https://doi.org/10.1016/0010-0285(71)90019-3

Bransford, J. D., \& Johnson, M. (1972). Contextual prerequisites for understanding: Some investigations of comprehension and recall. Journal of Verbal Learning and Verbal Behavior, 11, 717-726.

Brennan, A., Worrall, L., \& McKenna, K. (2005). The relationship between specific features of aphasia-friendly written material and comprehension of written material for people with aphasia: An exploratory study. Aphasiology, 19(8), 693-711.

https://doi.org/10.1080/02687030444000958

Brookshire, R. H., \& Nicholas, L. E. (1984). Comprehension of directly and indirectly stated main ideas and details in discourse by brain-damaged and non-brain-damaged listeners. Brain and Language, 21(1), 21-36. https://doi.org/10.1016/0093-934X(84)90033-6

Brookshire, R. H., \& Nicholas, L. E. (1993). Discourse Comprehension Test: Test Manual. Tucson, AZ, USA: Communication Skill Builders.

Caplan, D., \& Evans, L. (1990). The effects of syntactic structure on discourse comprehension in patients with parsing impairments. Brain and Language, 234, 206234.

Caspari, I., Parkinson, S. R., LaPointe, L. L., \& Katz, R. C. (1998). Working memory and 
aphasia. Brain and Cognition, 37(2), 205-223. https://doi.org/10.1006/brcg.1997.0970

Chall, J., \& Dale, E. (1995). Readability revisited: The new Dale-Chall readability formula. Northampton, MA: Brookline Books.

Corkill, A. J. (1992). Advance organizers: Facilitators of recall. Educational Psychology Review, 4(1), 33-67. https://doi.org/10.1007/BF01322394

Dale, E., \& Chall, J. (1948). A formula for predicting readability: Instructions. Educational Research Bulletin, 37-54.

Dexter, D. D., \& Hughes, C. A. (2011). Graphic organizers and students with learning disabilities: A meta-analysis. Learning Disability Quarterly, 34(1), 51-72.

Dietz, A., Hux, K., McKelvey, M. L., Beukelman, D. R., \& Weissling, K. (2009). Reading comprehension by people with chronic aphasia: A comparison of three levels of visuographic contextual support. Aphasiology, 23(7-8), 1053-1064. https://doi.org/10.1080/02687030802635832

Dietz, A., Knollman-Porter, K., \& Hux, K. (2014). Supported reading comprehension for people with aphasia: Photographic and linguistic supports. Journal of Medical Speech Language Pathology, 21(4), 319-331.

Eitel, A., Scheiter, K., Schüler, A., Nyström, M., \& Holmqvist, K. (2013). How a picture facilitates the process of learning from text: Evidence for scaffolding. Learning and Instruction, 28, 48-63. https://doi.org/10.1016/j.learninstruc.2013.05.002

Forster, K., \& Forster, J. (2003). DMDX: A Windows display program with millisecond accuracy. Journal of Behavior Research Methods, Instruments, \& Computers, 35(1), 116-121. https://doi.org/10.3758/BF03195503

Franks, J. J., \& Bransford, J. D. (1972). The acquisition of abstract ideas. Journal of Verbal Learning and Verbal Behavior, 11(3), 311-315. https://doi.org/10.1016/S0022$5371(72) 80092-6$ 
Glenberg, A. M., \& Langston, W. E. (1992). Comprehension of illustrated text: Pictures help to build mental models. Journal of Memory and Language, 31(2), 129-151. https://doi.org/10.1016/0749-596X(92)90008-L

Graesser, A. C., Singer, M., \& Trabasso, T. (1994). Constructing inferences during narrative text comprehension. Psychological Review, 101(3), 371-395. https://doi.org/10.1037/0033-295X.101.3.371

Hanna, G., Schell, L. M., \& Schreiner, R. (1977). Nelson Reading Skills Test. Chicago, IL: Riverside Publishing.

Harley, T. (2008). The psychology of Language: From data To theory (3rd ed.). Hove, United Kingdom: Psychology Press.

Humphreys, G., Riddoch, J., Samson, D., \& Bickerton, W. L. (2012). The Birmingham Cognitive Screen (BCoS). London: Psychology Press.

Johnston, P. (1984). Prior knowledge and reading comprehension test bias. Reading Research Quarterly, 19(2), 219-239.

Kintsch, W. (1988). The role of knowledge in discourse comprehension: A constructionintegration model. Advances in Psychology, 79(C), 107-153. https://doi.org/10.1016/S0166-4115(08)61551-4

Kintsch, W., Kozminsky, E., Streby, W. J., McKoon, G., \& Keenan, J. M. (1975). Comprehension and recall of text as a function of content variables. Journal of Verbal Learning and Verbal Behavior, 14(2), 196-214. https://doi.org/10.1016/S00225371(75)80065-X

Kintsch, W., \& Rawson, K. A. (2005). Comprehension. In M. J. Snowling \& C. Hulme (Eds.), The Science of Reading: A Handbook (pp. 209-226). Blackwell Publishing. https://doi.org/10.1002/9780470757642.ch12

Kintsch, W., \& van Dijk, T. A. (1978). Toward a model of text comprehension and 
production. Psychological Review, 85(5), 363-394. https://doi.org/10.1037/0033295X.85.5.363

Kjellén, E., Laakso, K., \& Henriksson, I. (2017). Aphasia and literacy-the insider's perspective. International Journal of Language and Communication Disorders, 52(5), 573-584. https://doi.org/10.1111/1460-6984.12302

Knollman-Porter, K., Wallace, S. E., Hux, K., Brown, J., \& Long, C. (2015). Reading experiences and use of supports by people with chronic aphasia. Aphasiology, 29(12), 1448-1472. https://doi.org/10.1080/02687038.2015.1041093

Lee, J. B., \& Sohlberg, M. M. (2013). Evaluation of attention training and metacognitive facilitation to improve comprehension in aphasia. American Journal of SpeechLanguage Pathology, 22, 318-334. https://doi.org/10.1044/1058-0360(2013/120099)S318

McKoon, G. (1977). Organization of information in text memory. Journal of Verbal Learning and Verbal Behavior, 16(2), 247-260. https://doi.org/10.1016/S0022$5371(77) 80050-9$

McKoon, G., \& Keenan, J. M. (1981). Response latencies to explicit and implicit statements as a function of the delay between reading and test. In W. Kintsch (Ed.), The Representation of Meaning in Memory. Hillsdale, NJ: Lawrence Erlbaum Associates.

McNamara, T., Miller, D., \& Bransford, J. (1991). Mental models and reading comprehension. In R. Barr, M. L. Kamil, P. B. Mosenthal, \& P. D. Pearson (Eds.), The Handbook of Reading Research, Vol. 2 (pp. 490-511). Hillsdale, NJ: Lawrence Erlbaum Associates, Inc.

McNeil, M. R., Odell, K., Tseng, C.-H., Schmitz, A., Gräsel, C., Rothstein, B., ... Caplan, D. (1993). Toward the integration of resource allocation into a general theory of aphasia. Clinical Aphasiology, 30(1), 797-804. https://doi.org/10.1007/s11145-016-9714-0 
Meng, K., \& Patty, D. (1991). Field dependence and contextual organizers. Journal of Educational Research, 84(3), 183-189.

Meteyard, L., Bruce, C., Edmundson, A., \& Oakhill, J. (2015). Profiling text comprehension impairments in aphasia. Aphasiology, 29(1), 1-28. https://doi.org/10.1080/02687038.2014.955388

Murray, L. L. (2002). Attention deficits in aphasia: Presence, nature, assessment, and treatment. Seminars in Speech and Language, 23(2), 107-116. https://doi.org/10.1055/s$2002-24987$

Nicholas, L. E., \& Brookshire, R. H. (1987). Error analysis and passage dependency of test items from a standardized test of multiple-sentence reading comprehension for aphasic and non-brain-damaged adults. Journal of Speech and Hearing Disorders, 52(4), 358366. Retrieved from http://ovidsp.ovid.com/ovidweb.cgi? $\mathrm{T}=\mathrm{JS} \& \mathrm{PAGE}=$ reference $\& \mathrm{D}=$ med2\&NEWS $=\mathrm{N} \& \mathrm{~A}$ $\mathrm{N}=2444768 \% 5 \mathrm{C}$

Parr, S. (1995). Everyday reading and writing in aphasia: Role change and the influence of pre-morbid literacy practice. Aphasiology, 9(3), 223-238. https://doi.org/10.1080/02687039508248197

Pearson, P. D., Hansen, J., \& Gordon, C. (1979). The effect of background knowledge on young children's comprehension of explicit and implicit information. Journal of Reading Behaviour, 11(3), 201-209. https://doi.org/10.1080/10862967909547324

Perrig, W., \& Kintsch, W. (1985). Propositional and situational representations of text. Journal of Memory and Language, 24(5), 503-518. https://doi.org/10.1016/0749$596 X(85) 90042-7$

Purdy, M., Coppens, P., Madden, E. B., Mozeiko, J., Patterson, J., Wallace, S. E., \& Freed, D. (2018). Reading comprehension treatment in aphasia: a systematic review. 
Aphasiology, 33(6), 629-651. https://doi.org/10.1080/02687038.2018.1482405

R Core Team. (2018). R: A language and environment for statistical computing. R

Foundation for Statistical Computing, Vienna, Austria. Retrieved from https://www.rproject.org/

Rayner, K. (2009). Eye movements and attention in reading, scene perception, and visual search. The Quarterly Journal of Experimental Psychology, 62(8), 1457-1506. https://doi.org/10.1080/17470210902816461

Rayner, K., Pacht, J. M., \& Duffy, S. A. (1994). Effects of prior encounter and global discourse bias on the processing of lexically ambiguous words: Evidence from eye fixations. Journal of Memory and Language, 33(4), 527-544.

https://doi.org/10.1006/jmla.1994.1025

Rose, T., Worrall, L. E., Hickson, L. M., \& Hoffmann, T. C. (2011). Exploring the use of graphics in written health information for people with aphasia. Aphasiology, 25(12), 1579-1599. https://doi.org/10.1080/02687038.2011.626845

Rose, T., Worrall, L. E., Hickson, L. M., \& Hoffmann, T. C. (2012). Guiding principles for printed education materials: Design preferences of people with aphasia. International Journal of Speech-Language Pathology, 14(1), 11-23.

https://doi.org/10.3109/17549507.2011.631583

Schretlen, D. J. (2010). Modified Wisconsin Card Sorting Test ${ }^{\circledR}$ (M-WCST): Professional Manual. PAR.

Schweppe, J., Eitel, A., \& Rummer, R. (2015). The multimedia effect and its stability over time. Learning and Instruction, 38, 24-33. https://doi.org/10.1016/j.learninstruc.2015.03.001

Smith, E. E., \& Swinney, D. A. (1992). The role of schemas in reading text: A real-time examination. Discourse Processes, 15(3), 303-316. 
https://doi.org/10.1080/01638539209544814

Stachowiak, F. J., Huber, W., Poeck, K., \& Kerschensteiner, M. (1977). Text comprehension in aphasia. Brain and Language, 4(2), 177-195. https://doi.org/10.1016/0093934X(77)90016-5

Swinburn, K., Porter, G., \& Howard, D. (2004). Comprehensive Aphasia Test. Hove, United Kingdom: Psychology Press.

Thomas, C. A., \& Jackson, S. T. (1997). The validity of reading comprehension therapy materials. Journal of Communication Disorders, 30(3), 231-243. https://doi.org/10.1016/S0021-9924(96)00075-5

Thorndyke, P. W. (1968). The role of inferences in discourse comprehension. Journal of Verbal Learning and Verbal Behavior, 15(4), 437-446. https://doi.org/10.1016/S00225371(76)90039-6

Tompkins, C. A., Bloise, C. G. R., Timko, M. L., \& Baumgaertner, A. (1994). Working memory and inference revision in brain-damaged and normally aging adults. Journal of Speech and Hearing Research, 37(4), 896-912. https://doi.org/10.1044/jshr.3704.896

Tuinman, J. J. (1974). Determining the passage dependency of comprehension questions in 5 major tests. Reading Research Quarterly, 9(2), 206-223.

van Dijk, T. A., \& Kintsch, W. (1983). Strategies of Discourse Comprehension. New York: Academic Press.

Walker, C. H., \& Meyer, B. J. F. (1980). Integrating different types of information in text. Journal of Verbal Learning and Verbal Behavior, 19(263-275).

Waller, M. R., \& Darley, F. L. (1978). The influence of context on the auditory comprehension of aphasic subjects. Journal of Speech and Hearing Research, 21, 732745.

Warrington, E. K. (1996). The Camden Memory Tests Manual. Hove, United Kingdom: 
Psychology Press.

Watter, K., Copley, A., \& Finch, E. (2016). Discourse level reading comprehension interventions following acquired brain injury: a systematic review. Disability and Rehabilitation, 39(4), 315-337. https://doi.org/10.3109/09638288.2016.1141241

Webb, W. G., \& Love, R. J. (1983). Reading problems in chronic aphasia. Journal of Speech and Hearing Disorders, 48(2), 164-171. https://doi.org/10.1044/jshd.4802.164

Webster, J., Morris, J., Connor, C., Horner, R., McCormac, C., \& Potts, A. (2013). Text level reading comprehension in aphasia: What do we know about therapy and what do we need to know? Aphasiology, 27(11), 1362-1380.

https://doi.org/10.1080/02687038.2013.825760

Webster, J., Morris, J., Howard, D., \& Garraffa, M. (2018). Reading for meaning: What influences paragraph understanding in aphasia? American Journal of Speech-Language Pathology, 27(1S), 423-437. https://doi.org/10.1044/2017_AJSLP-16-0213

Webster, J., Samouelle, A., \& Morris, J. (2018). “The brain can't cope”: Insights about reading from people with chronic aphasia. PsyArXiv, 1-30. https://doi.org/10.31234/osf.io/p8xh4

Wiley, J., \& Rayner, K. (2000). Effects of titles on the processing of text and lexically ambiguous words: Evidence from eye movements. Memory and Cognition, 28(6), 10111021. https://doi.org/10.3758/BF03209349

Wilhite, S. C. (1989). Headings as memory facilitators: The importance of prior knowledge. Journal of Educational Psychology, 81(1), 115-117. https://doi.org/10.1037/00220663.81 .1 .115

Wilson, L., \& Read, J. (2016). Do particular design features assist people with aphasia to comprehend text? An exploratory study. International Journal of Language and Communication Disorders, 51(3), 346-354. https://doi.org/10.1111/1460-6984.12206 
Yuill, N., \& Joscelyne, T. (1988). Effect of organizational cues and strategies on good and poor comprehenders' story understanding. Journal of Educational Psychology, 80(2), 152-158. https://doi.org/10.1037/0022-0663.80.2.152 